Pharmaceutical nanotechnology

\title{
Folic acid-functionalized human serum albumin nanocapsules for targeted drug delivery to chronically activated macrophages
}

\author{
Alexandra Rollett ${ }^{\mathrm{a}}$, Tamara Reiter ${ }^{\mathrm{a}}$, Patricia Nogueira ${ }^{\mathrm{b}}$, Massimiliano Cardinale ${ }^{\mathrm{a}}$, Ana Loureiro ${ }^{\mathrm{c}, \mathrm{d}}$, \\ Andreia Gomes $^{\mathrm{d}}$, Artur Cavaco-Paulo ${ }^{\mathrm{c}}$, Alexandra Moreira ${ }^{\mathrm{b}}$, Alexandre M. Carmo ${ }^{\mathrm{b}, \mathrm{e}}$, Georg M. Guebitz ${ }^{\mathrm{a}, \mathrm{f}, *}$
}

\author{
${ }^{a}$ Graz University of Technology, Institute of Environmental Biotechnology, Petersgasse 12, 8010 Graz, Austria \\ b IBMC - Instituto de Biologia Molecular e Celular, Rua do Campo Alegre 823, 4150-180 Porto, Portugal \\ c University of Minho, Dept. Textile Eng., 4800-058 Guimaraes, Portugal \\ d University of Minho, Biology Department, Campus de Gualtar, 4710-057 Braga, Portugal \\ e ICBAS - Instituto de Ciências Biomédicas Abel Salazar, Universidade do Porto, Rua Jorge Viterbo Ferreira, 228, 4050-313 Porto, Portugal \\ ${ }^{\mathrm{f}}$ Austrian Centre of Industrial Biotechnology, Petersgasse 14, $8010 \mathrm{Graz}$, Austria
}

\section{A R T I C L E I N F O}

\section{Article history:}

Received 21 December 2011

Received in revised form 15 February 2012

Accepted 19 February 2012

Available online 25 February 2012

\section{Keywords:}

Targeted

Drug delivery

Albumin nanocapsules

Folate receptor

Macrophages

\begin{abstract}
A B S T R A C T
Activated synovial macrophages play a key role in Rheumatoid Arthritis (RA). Recent studies have shown that folate receptor beta (FR $\beta$ ) is specifically expressed by activated macrophages. Therefore a folate-based nanodevice would provide the possibility of delivering therapeutic agents to activated macrophages without affecting normal cells and tissues.

This study shows for the first time the sonochemical preparation of HSA nanocapsules avoiding toxic cross linking chemicals and emulsifiers used in other methods.

Production of HSA nanocapsules was optimized leading to a diameter of $443.5 \pm 9.0 \mathrm{~nm}$ and a narrow size distribution indicated by a polydispersity index (PDI) of $0.066 \pm 0.080$. Nanocapsules were surface modified with folic acid (FA) and the FA content was determined to be 0.38 and 6.42 molecules FA per molecule HSA, depending on the surplus of FA employed. Dynamic light scattering was used to determine size, PDI and zetapotential of the produced nanocapsules before and after surface modification. FA distribution on the surface of HSA nanocapsules was localized three-dimensionally after fluorescence labeling using confocal laser scanning microscopy (CLSM). Furthermore, specific binding and internalization of HSA nanocapsules by FR $\beta$-positive and FR $\beta$-negative macrophages, obtained from human peripheral blood mononuclear cells, was demonstrated by flow cytometry. FR $\beta$-expressing macrophages showed an increased binding for FA-modified capsules compared with those without FA.
\end{abstract}

(C) 2012 Elsevier B.V. All rights reserved.

\section{Introduction}

Rheumatoid Arthritis (RA) is a chronic, systemic autoimmune disorder that is characterized by inflammation of the joints. Chronically activated synovial macrophages play a key role in this inflammatory disease with numbers and level of macrophage activation correlating with the extent of joint inflammation and tissue degradation (Adamopoulos et al., 2006; Schett, 2008). Amongst others, some therapies are designed to eliminate the entire population of macrophages. However, this can cause severe side effects since macrophages have an essential function in fighting infectious

\footnotetext{
* Corresponding author at: Graz University of Technology, Institute of Environmental Biotechnology, Petersgasse 12, 8010 Graz, Austria. Tel.: +43 3168738312; fax: +433168738815 .

E-mail address: guebitz@tugraz.at (G.M. Guebitz).
}

diseases and promoting tissue repair. Consequently, specific elimination of the sub-population of chronic activated macrophages has been suggested as an alternative to the elimination of the entire macrophage population. Delivery of therapeutic agents selectively to pro-inflammatory cells would avoid toxicity and collateral damage to healthy cells. Recent studies have shown that the folate receptor beta (FR $\beta$ ), which displays a high affinity for FA, is specifically expressed by activated macrophages (Puig-Kröger et al., 2009; Ross et al., 1999; Van Der Heijden et al., 2009). Therefore a folate-based nanodevice would provide the possibility of delivering therapeutic agents to activated macrophages without affecting normal cells and tissues.

Various types of folate conjugated drug delivery systems, such as liposomes (Gabizon et al., 1999), copolymer nanoparticles (Stella et al., 2000), baculovirus (Kim et al., 2007) and nanoparticles produced by HSA (Ulbrich et al., 2011) were previously described. Due to their uniquely diverse structures and functions, proteins are 
described to be highly interesting for the creation of new materials (Witus and Francis, 2011). HSA shows various valuable properties such as biodegradability, biocompatibility, effective drug loading capacity due to drug-binding properties of natural albumin and water solubility (Müller et al., 1996). HSA provides several functional groups on the surface which can be easily used for surface modification. Based on coupling to these functional groups, FA could be specifically attached onto the surface of the nanodevice rendering it recognizable by activated macrophages. However, many conventional techniques for the preparation of protein based nanocapsules involve cross-linking with toxic chemicals (Langer et al., 2003). Here we describe a strategy for the preparation of HSA nanocapsules which avoids toxic cross-linking chemicals such as glutaraldehyde commonly used in the desolvation.

Sonochemical methods have previously been described for the preparation of protein microspheres with an average diameter of $2.5 \mu \mathrm{m}$ (Grinstaff and Suslick, 1991; Silva et al., 2011). However, it was reported that small nanoparticles were taken up more efficiently by the cells, when compared to such microparticles (Suri et al., 2007; Panyam and Labhasetwar, 2003). Likewise, in vivo experiments demonstrated that nanoparticles show a better performance since they diffused throughout the sub-mucosal layers while microparticles were predominantly localized in the epithelial lining (Desai et al., 1996). Consequently, in this study, stable FA-functionalized HSA nanocapsules in a size range of $500 \mathrm{~nm}$ were developed. The absence of crosslinking chemicals and emulsifiers in the production of these nanocapsules also provides an advantage from the economical point of view. Confocal laser scanning microscopy (CLSM) has the advantage over conventional light microscopy and scanning electron microscopy of gaining information about the three dimensional localization of fluorescence labeled compounds (Lamprecht et al., 2000). Thus, we used CLSM to monitor the reaction conditions and allow three-dimensional analysis of FA distribution on the surface of HSA capsules after fluorescence labeling of FA and HSA. Furthermore, specific internalization of FA modified nanocapsules was shown in primary human macrophages.

\section{Materials and methods}

\subsection{Materials}

Human serum albumin (HSA), folic acid (FA), N-(3dimethylaminopropyl)-N-ethylcarbodiimide hydrochloride (EDAC), N-hydroxysuccinimide (NHS), n-dodecane, dimethylformamide (DMF), fluorescein 5(6)-isothiocyanate (FITC) and fluorescent red mega 520 NHS ester (fluorescent red) were purchased from Sigma-Aldrich (Steinheim, Germany). All other reagents were used in analytical grade.

\subsection{Methods}

\subsubsection{Fluorescent labeling}

For CLSM studies FA and HSA were labeled with fluorescent dyes prior to capsule production. FA was labeled with fluorescent red. Therefore, $1 \mathrm{mg}$ of FA was dissolved in $200 \mu \mathrm{L}$ buffer $(50 \mathrm{mM}$ bicarbonate buffer, $\mathrm{pH}$ 9) and $150 \mu \mathrm{L}$ of DMF were added. $1 \mathrm{mg}$ of fluorescent red was dissolved in $50 \mu \mathrm{L}$ DMF. $14 \mu \mathrm{L}$ of fluorescence red stock solution ( 1 equiv.) were mixed with $70 \mu \mathrm{L}$ of FA stock solution (1 equiv.). $100 \mu \mathrm{L}$ of DMF were added and the mixture was shaken for $12 \mathrm{~h}$ at $25^{\circ} \mathrm{C}$. The mixture was purified by SEC using a HiTrap Desalting column (GE Healthcare Europe GmbH, Vienna, Austria) installed on an Äkta Purifier system (Amersham Pharmacia Biotech, Uppsala, Sweden), with $50 \mathrm{mM}$ potassium phosphate and $100 \mathrm{mM} \mathrm{NaCl}(\mathrm{pH} 7)$ as eluent, at the flow rate of $1 \mathrm{~mL} \mathrm{~min}^{-1}$ to
Table 1

Reaction conditions for the preparation of HSA nanocapsules by ultrasonication.

\begin{tabular}{lcll}
\hline Sample & Treatment time [min] & Amplitude control [\%] & Pulsation [\%] \\
\hline 1 & 5 & 50 & 10 \\
2 & 5 & 50 & 50 \\
3 & 5 & 70 & 10 \\
4 & 5 & 70 & 50 \\
5 & 10 & 50 & 10 \\
6 & 10 & 50 & 50 \\
7 & 10 & 70 & 10 \\
8 & 10 & 70 & 50 \\
9 & 10 & 60 & 20 \\
\hline
\end{tabular}

remove unlinked FA. Fractions which showed absorbance at $520 \mathrm{~nm}$ for fluorescent red and $368 \mathrm{~nm}$ for FA, respectively were collected.

For labeling with FITC, $4 \mathrm{~mL}$ of a HSA solution $\left(10 \mathrm{mg} \mathrm{mL}^{-1}\right.$ in bicarbonate buffer, pH 9.2) were mixed with $200 \mu \mathrm{L}$ of FITC solution ( $5 \mathrm{mg} \mathrm{mL}^{-1}$ in DMSO). This mixture was shaken for $4 \mathrm{~h}$ at $25^{\circ} \mathrm{C}$ under light protection. Thereafter the mixture was purified by SEC using a HiPrep 26/10 Desalting column (GE Healthcare Europe $\mathrm{GmbH}$, Vienna, Austria) using the same settings like described above at a flow rate of $3 \mathrm{~mL} \mathrm{~min}^{-1}$ to remove excess FITC. Fractions showing absorbance at 280 and $485 \mathrm{~nm}$ were collected and reduced to a volume of $4 \mathrm{~mL}$ using a Vivaspin $30 \mathrm{kD}$ centrifugal separator at $5000 \mathrm{rpm}$ using Biofuge primo (Heraeus, Buckinghamshire, England).

\subsubsection{Production of HSA nanocapsules}

For nanocapsule production, a mixture of $50 \%$ FITC-labeled and $50 \%$ unlabeled HSA was used. $10 \mathrm{~mL}$ HSA-solution $\left(2 \mathrm{mg} \mathrm{mL}^{-1}\right.$ in $100 \mathrm{mM}$ potassium phosphate buffer, $\mathrm{pH} 8$ ) were combined with $6.6 \mathrm{~mL}$ of dodecane. This mixture was sonicated using a $13 \mathrm{~mm}$ disrupter horn connected to Branson Sonifier 250 on ice using the time, amplitude control and pulsation parameters as specified below (Table 1). Horn amplitudes are specified for certain amplitude control settings $(21.0 \mu \mathrm{m}$ for an amplitude control setting of $10 \%$; $76.0 \mu \mathrm{m}$ for $50 \%, 145.0 \mu \mathrm{m}$ for $100 \%$ ). A power of $70 \mathrm{~W}$ was required to maintain the amplitude for a given amplitude control setting of $50 \%$. For phase separation the samples were stored $4{ }^{\circ} \mathrm{C}$ for $12 \mathrm{~h}$. Thereafter, the organic phase was removed and the nanocapsules were washed three times with $100 \mathrm{mM}$ sodium-phosphate buffer, $\mathrm{pH} 7.4$ by centrifuging ( $5 \mathrm{~min}, 5000 \mathrm{rpm}$ ) and pouring away the supernatant. The solution was filtered through a $0.8 \mu \mathrm{m}$ syringe filter to remove bigger capsules.

\subsubsection{Surface modification}

Coupling of FA on HSA nanocapsules: FA was coupled covalently on the surface of HSA nanocapsules in different concentrations. Stock solutions of FA, NHS and EDAC were prepared in $130 \mathrm{mM}$ $\mathrm{NaHCO}_{3}$ buffer ( $\mathrm{pH}$ 7) as follows, FA: $5 \mathrm{mg} \mathrm{mL}^{-1}$, NHS: $20 \mathrm{mg} \mathrm{mL}^{-1}$, EDAC: $20 \mathrm{mg} \mathrm{mL}^{-1}$. FA was mixed with 50 equiv. of EDAC and NHS and the mixture was activated for $20 \mathrm{~min}$ at $25^{\circ} \mathrm{C}$. Thereafter, the HSA nanocapsule solution was combined with different concentrations of activated FA (10 equiv., 50 equiv. to HSA concentration) and reacted for $12 \mathrm{~h}$ at room temperature. Subsequently, the capsules were separated from uncoupled FA by washing five times with $\mathrm{ddH}_{2} \mathrm{O}$ using Vivaspin $30 \mathrm{kD}$ at $5000 \mathrm{rpm}$.

\subsubsection{Analysis}

FA and HSA concentration: The concentration of FA in free conjugates was determined photometrically. A calibration curve of FA samples with concentrations from 1 to $500 \mu \mathrm{g} \mathrm{mL}^{-1}$ in $130 \mathrm{mM}$ $\mathrm{NaHCO}_{3}$ buffer ( $\mathrm{pH} \mathrm{7}$ ) was recorded at $368 \mathrm{~nm}$. The HSA concentration was determined using Roti ${ }^{\circledR}$-Nanoquant (Carl Roth $\mathrm{GmbH}+\mathrm{Co}$. KG, Karlsruhe, Germany) which is based on the method of Bradford (Bradford, 1976). For the determination of FA and HSA 
concentrations in capsules, samples were freeze dried and the dry powder was re-dissolved in $130 \mathrm{mM} \mathrm{NaHCO}_{3}$ buffer ( $\left.\mathrm{pH} 7\right)$ to disintegrate capsules and give a solution of free HSA and HSA-FA molecules. Disintegration of capsules was followed by monitoring the number mean of particles using DLS. The FA concentration was determined by calculating the area of the absorbance peak at $368 \mathrm{~nm}$ and interpolation. For this purpose, a calibration curve was recorded with different concentrations of FA in the presence of HSA nanocapsules as background.

The interference of HSA and FA on the different analysis methods was tested. Mixtures of HSA and FA with known concentrations of both analytes were prepared and the concentrations were determined with the described methods. Measured and theoretical values were compared to confirm that FA and HSA have no influence on the analysis methods.

Confocal laser scanning microscopy: Surface modified HSAcapsules in the micron range were used as model to perform CLSM experiments with a Leica TCS SPE Confocal microscope (Leica Microsystems GmbH, Mannheim, Germany). Laser light wavelengths of $532 \mathrm{~nm}$ and $488 \mathrm{~nm}$ were used for the excitation of fluorescent red and FITC, respectively. The emitted light was detected in the range of $644-684 \mathrm{~nm}$ for fluorescent red and $500-556 \mathrm{~nm}$ for FITC. For every channel and every field of view, laser intensity, photomultiplier gain and offset were individually modified to optimize the signal/noise ratio. Confocal stacks were acquired with an ACS APO 63.0 $\times 1.30$ oil objective by applying a $Z$-step of $6.01 \mu \mathrm{m}$. Volume rendering and three dimensional models were created with the software Imaris7.0 (Bitplane, Zurich, Switzerland).

Dynamic light scattering (DLS): The mean size of HSA nanocapsules was determined by DLS using Zetasizer Nano ZS (Malvern Instruments $\mathrm{GmbH}$, Herrenberg, Germany). Measurements were performed in triplicates at $25^{\circ} \mathrm{C}$ with angle detection at $173^{\circ}$. Nanocapsules were diluted with $100 \mathrm{mM}$ sodium-phosphate buffer, pH 7.4-0.1 $\mathrm{mg} \mathrm{mL}^{-1}$. Size distribution was characterized by the PDI. Zeta potential was determined based on a combination of laser Doppler velocimetry and phase analysis light scattering using Zetasizer Nano ZS.

\subsubsection{Cell studies}

Human peripheral blood mononuclear cells were isolated from buffy coats of healthy volunteers from the Instituto Português do Sangue (IPS, Porto, Portugal) by centrifugation over Lymphoprep (Axis-Shield) and monocytes were further purified by magnetic cell sorting using CD14 microbeads (Miltenyi Biotec). Monocytederived macrophages were generated in RPMI 1640 (supplemented with $10 \% \mathrm{FCS}, 100 \mathrm{U} \mathrm{mL}^{-1}$ penicillin and $100 \mu \mathrm{g} \mathrm{mL}^{-1}$ streptomycin) in the presence of $50 \mathrm{ng} \mathrm{mL}^{-1} \mathrm{M}-\mathrm{CSF}$ (Pepro Tech) for 7 days followed by an activation of $24 \mathrm{~h}$ with $20 \mathrm{ng} \mathrm{mL}^{-1} \mathrm{IL}-4$ (Pepro Tech).

The presence of surface FR $\beta$ in macrophages was evaluated by flow cytometry using a monoclonal FR $\beta$ antibody (Exbio, Prague, Czech Republic). Prior to antibody staining, Fc receptors were blocked with FcR Blocking Reagent (Miltenyi Biotec). An isotype-matched monoclonal antibody was used as negative control. Flow cytometry analysis was performed with a FACSCalibur flow cytometer (BD Biosciences) and data was analyzed using FlowJo software version 8.7 (Tree Star Inc.).

To obtain FR $\beta$-positive and FR $\beta$-negative macrophages, monocytes were incubated with $10 \mathrm{ng} \mathrm{mL}^{-1}$ GM-CSF (Pepro Tech) for 7 days. FR $\beta$-positive and FR $\beta$-negative macrophages were then separated using a FACSaria cell sorter (BD Biosciences).

Binding and internalization of HSA nanocapsules by macrophages was assessed by flow cytometry while all tests were performed in duplicates. Briefly, macrophages were incubated for $1.5 \mathrm{~h}$ with $0.1 \mathrm{mg} \mathrm{mL}^{-1} \mathrm{HSA}$ nanocapsules in complete RPMI at $37^{\circ} \mathrm{C}$ (binding and internalization allowed) or at $4{ }^{\circ} \mathrm{C}$ (binding only). After incubation cells were washed with PBS ( $\mathrm{pH}$ 7.4) or with acidic $\mathrm{NaCl} 0.9 \%(\mathrm{pH} \mathrm{3}$ ). Data was acquired on a FACScalibur flow cytometer. The binding was determined as the geometrical mean fluorescence intensity of the HSA nanocapsules corrected for the background staining of cells not incubated with the nanocapsules. Mean fluorescence intensity equal or below 1.0 means no binding.

The viability of macrophages in the presence of the HSA nanocapsules was evaluated using the Resazurin assay. This method is based on the ability of living cells to convert the dye Resazurin into a fluorescent product (Resorufin). MCSF-differentiated macrophages were incubated with different concentrations of HSA-nanocapsules for $24 \mathrm{~h}$ at $37^{\circ} \mathrm{C}$, followed by incubation with Resazurin for $4 \mathrm{~h}$. Fluorescence was then read at $560 / 590 \mathrm{~nm}$ in a plate-reading fluorometer (SpectraMax Gemini XS, Molecular Devices).

\section{Results and discussion}

\subsection{Preparation of HSA nanocapsules}

A sonochemical method for the production of FA-functionalized HSA nanocapsules was developed. The strategy presented here avoided the use of toxic chemicals for cross-linking and aimed at a narrow size distribution to allow delivery of therapeutic agents to activated macrophages without affecting normal cells and tissues.

A commonly used method for the preparation of albumin nanoparticles is the desolvation technique (Langer et al., 2003). Using this method, nanoparticles in a size range between 150 and $280 \mathrm{~nm}$ can be prepared. A disadvantage of this method is the use of toxic glutaraldehyde as crosslinker to stabilize the prepared nanoparticles. The use of toxic cross-linkers for the preparation of protein aqueous microspheres can be avoided by using sonochemical strategies. However, previously capsules in a size range of $2.5 \mu \mathrm{m}$ were achieved (Grinstaff and Suslick, 1992), which is far too big in order to allow for specific cell internalization. Particles in this size range are recognized by macrophages as foreign particles and are consequently taken up through phagocytosis (Ahsan et al., 2002). This would not only lead to elimination of the particles before showing a therapeutic effect, but would also affect healthy macrophages. In non-phagocytic cells nanoparticles with a size of $100 \mathrm{~nm}$ showed a relatively higher intracellular uptake compared to microparticles (Suri et al., 2007; Panyam and Labhasetwar, 2003). Therefore, a specific non-phagocytic uptake due to recognition of folic acid by the FR $\beta$ can only be achieved with nanoparticles. Size is also an important factor for in vivo experiments since it was shown that $100 \mathrm{~nm}$ particles diffused throughout the sub-mucosal layers while microparticles were predominantly localized in the epithelial lining (Desai et al., 1996).

In this study, optimization of energetic and time parameters in ultrasound-based formation of nanocapsules lead to an average diameter of below $500 \mathrm{~nm}$ and a narrow size distribution. Nine combinations of amplitude, pulsation and total treatment time were tested while the $\mathrm{pH}$ value was fixed to $\mathrm{pH} 8$, which was previously demonstrated to be the optimum for protein nanoparticle production (Sebak et al., 2010).

DLS measurements of HSA-capsules after several washing steps showed a broad size distribution indicated by a PDI value around 0.3 in all samples. Data analysis proved that two populations of particles with diameters around $300 \mathrm{~nm}$ and around $900 \mathrm{~nm}$, respectively, were obtained. Consequently, a filtration step was incorporated to eliminate the larger diameter particle population. Testing filter pore sizes of $1.0 \mu \mathrm{m}$ and $0.8 \mu \mathrm{m}$, with the smaller pore size particles larger than $800 \mathrm{~nm}$ were successfully eliminated. 


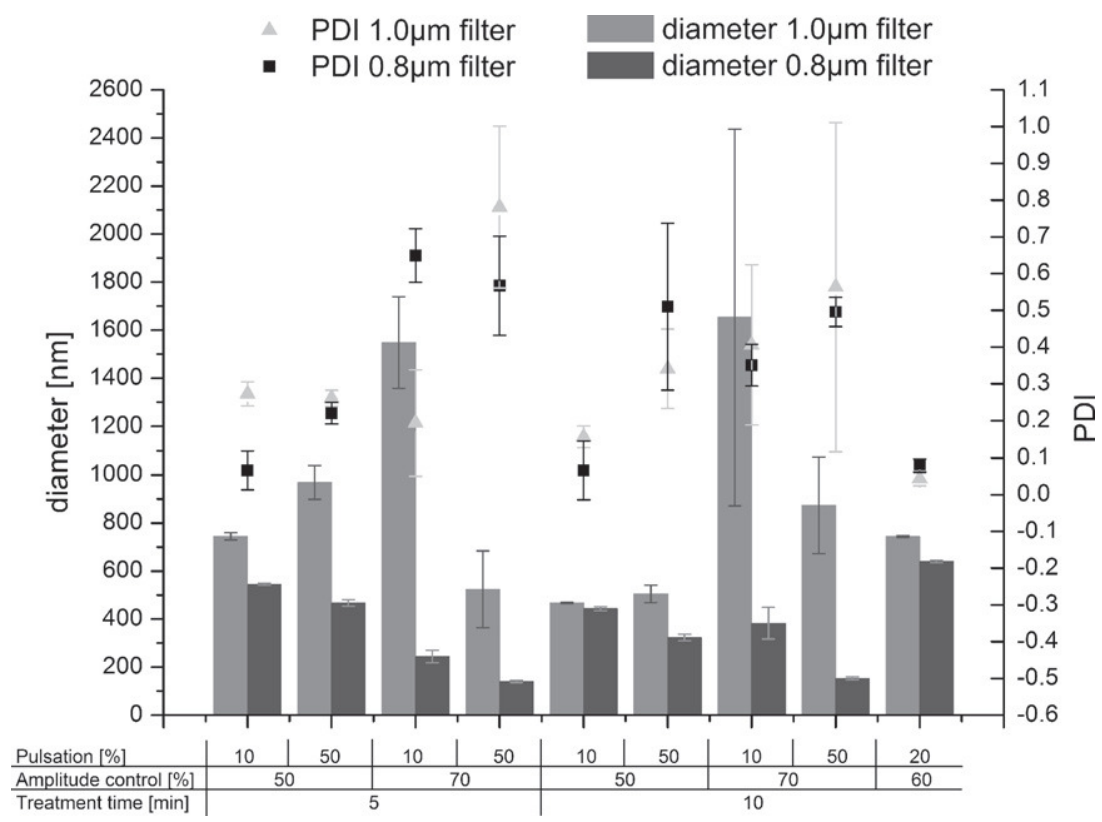

Fig. 1. Parameter (pulsation, amplitude control, treatment time) optimization of ultrasonic production of HSA nanocapsules towards small diameters and PDI (polydispersity index). Diameter and PDI were measured after filtration (pore size 1.0 and $0.8 \mu \mathrm{m}$ ).

Moreover, a narrow size distribution with minimum PDI values of around 0.07 was obtained.

Thus, in all subsequent experiments an amplitude control of $50 \%$, pulsation $10 \%$ and 10 min treatment time for sonication were used. These optimized energetic and time parameters gave small nanocapsules with a diameter of $443.5 \pm 9.0 \mathrm{~nm}$ and a narrow size distribution indicated by a PDI of $0.066 \pm 0.080$ (Fig. 1).

\subsection{Surface modification}

For recognition by activated macrophages, FA was attached to the surface of the nanocapsules via the carboxylic end of the molecule, since the pteridine residue is responsible for FR $\beta$ recognition and therefore cannot be modified. The water soluble, heterobifunctional cross-linker EDAC was used to activate FAcarboxylic groups which further react with primary amines located on the capsule surface.

Preliminary results indicated that disintegration of nanocapsules was necessary prior to spectroscopic quantification of FA at $368 \mathrm{~nm}$ and HSA quantification based on a modified Bradford assay. To exclude any interference of HSA and FA absorption, calibration curves for FA quantification at $368 \mathrm{~nm}$ were recorded in the presence of disintegrated HSA-nanocapsules as background. Disintegration of nanocapsules was successfully demonstrated by using DLS analysis showing a lower number mean of $73.39 \pm 30.98 \mathrm{~nm}$ and a PDI of $0.475 \pm 0.186$.

Capsules with two different concentrations of FA were produced to compare the cell internalization ability as a function of FA amount linked on the surface. The FA content on capsules was determined to be 0.38 and 6.42 molecules FA per molecule HSA respectively (Table 2). A maximum coupling yield of around $12.8 \%$

Table 2

Concentration of FA on nanocapsules calculated as molar ratio of FA molecules per HSA molecules used for the coupling reaction vs. FA concentration determined after coupling reaction.

\begin{tabular}{ll}
\hline Amount FA per HSA $\left[\mathrm{mol} \mathrm{mol}^{-1}\right]$ & FA linked on $\mathrm{HSA}\left[\mathrm{mol} \mathrm{mol}^{-1}\right]$ \\
\hline 10 & $0.38 \pm 0.02$ \\
50 & $6.42 \pm 0.18$ \\
\hline
\end{tabular}

was achieved when a 50 fold molar excess of FA was used for the coupling experiment.

\subsubsection{Zetapotential, size, PDI}

Size and PDI measurements showed that filtration is the essential step to obtain nanocapsules with a narrow size distribution. After filtration only nanocapsules with a diameter of around $500 \mathrm{~nm}$ and a PDI of 0.2 (Fig. 2) were found. An increase in polydispersity could be observed with higher amounts of FA linked on the capsule surface. This effect can be correlated with results from CLSM analysis where some inhomogeneity regarding capsule modification was seen. The zetapotential of the nanocapsules was around $-20 \mathrm{mV}$ and only a slight deviation could be observed after FA modification. With CLSM analysis it was verified that no aggregate formation occurred, even though it has been previously described that a zetapotential above $( \pm) 30 \mathrm{mV}$ was the balance point between stable and unstable suspensions (Mohanraj and Chen, 2006).

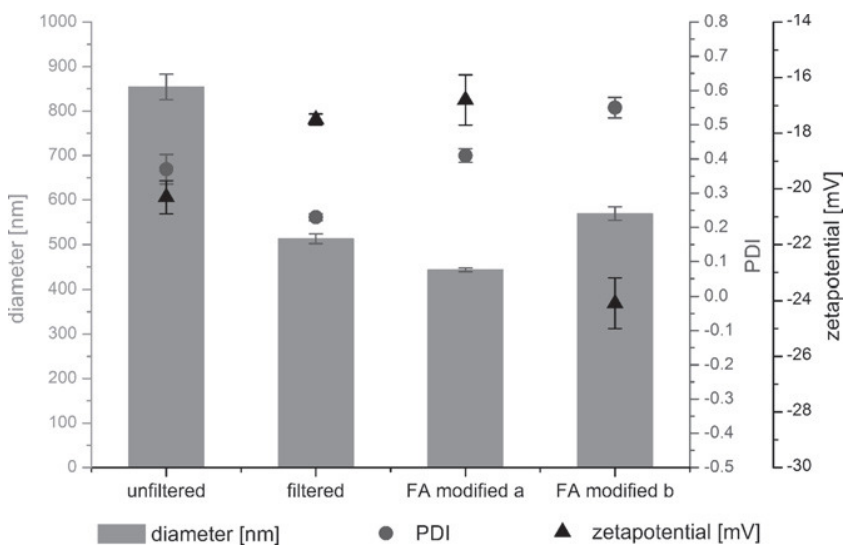

Fig. 2. Diameter [nm], PDI and zetapotential [mV] of HSA nanocapsules before and after filtration (pore size $0.8 \mu \mathrm{m}$ ) and after surface modification with FA in different molar excess (a) 0.38 mol FA per mol HSA and (b) $6.42 \mathrm{~mol} \mathrm{FA} \mathrm{per} \mathrm{mol} \mathrm{HSA,} \mathrm{both}$ filtered. 

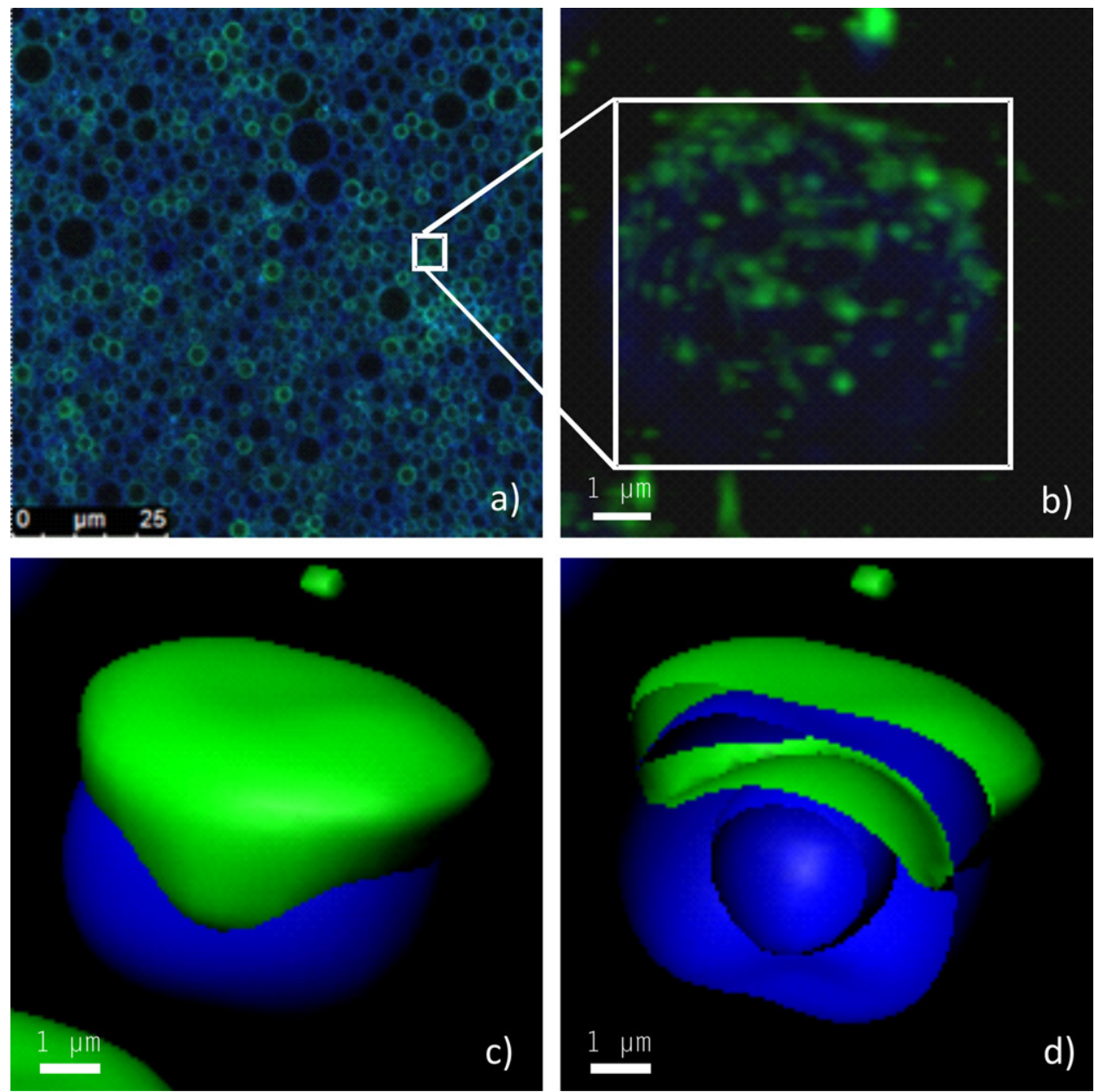

Fig. 3. CLSM image (a) and 3D reconstruction (b-d) of FITC-labeled HSA nanocapsules carrying fluorescent red labeled FA on the capsule surface. Blue: HSA, green: FA. (For interpretation of the references to color in this figure legend, the reader is referred to the web version of the article.)

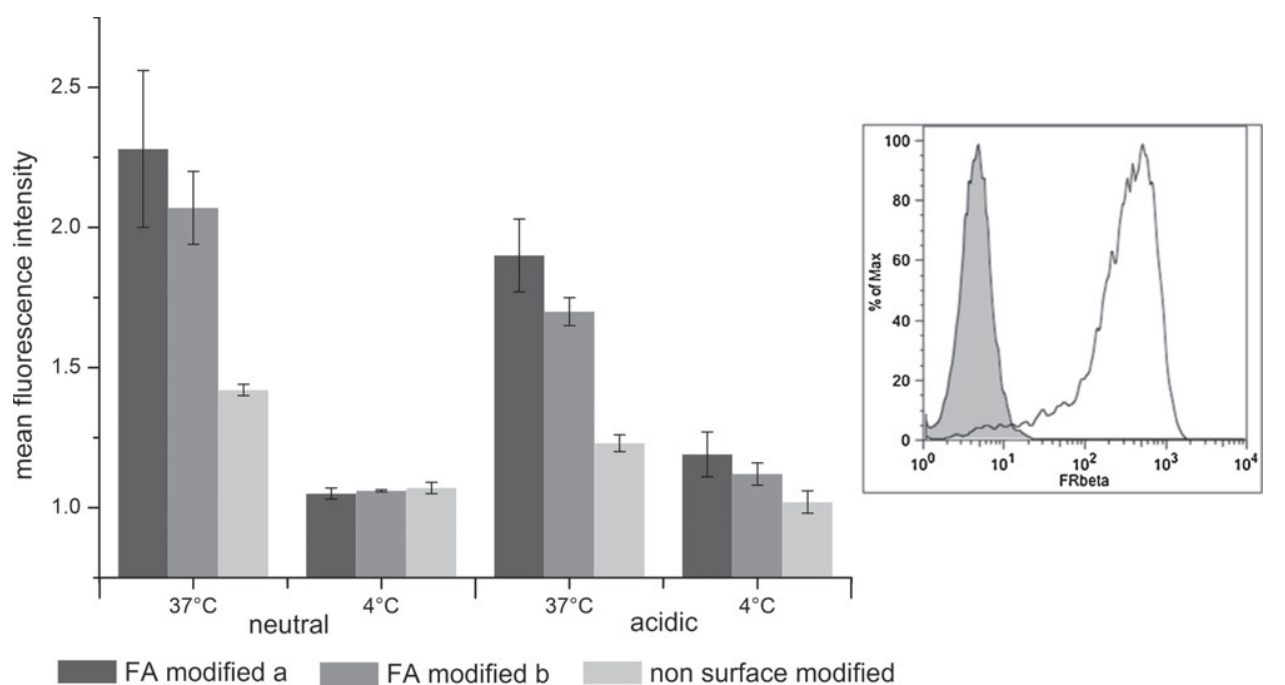

Fig. 4. (Left) Binding/internalization of FITC-conjugated HSA nanocapsules FA (a) 0.38 FA per HSA [mol mol ${ }^{-1}$ ], FA (b) 6.42 FA per HSA [mol mol ${ }^{-1}$ ] by macrophages after $1.5 \mathrm{~h}$ incubation at $37^{\circ} \mathrm{C}$ or $4^{\circ} \mathrm{C}$ followed by neutral or acidic washing. The binding was determined by flow cytometry as the geometrical mean fluorescence intensity of the HSA nanocapsules. Mean fluorescence intensity equal or below 1.0 means no binding. (Right) FR $\beta$ expression (flow cytometry analysis) in human activated macrophages. Macrophages were obtained by incubation with $50 \mathrm{ng} \mathrm{mL}^{-1} \mathrm{M}$-CSF for 7 days followed by 1 day of activation with $20 \mathrm{ng} \mathrm{mL}^{-1} \mathrm{IL}-4$. Solid black line represents FR $\beta$ expression and filled histogram represents the isotype control. 


\subsubsection{CLSM characterization}

Amongst other methods, CLSM was used for the characterization of surface modified HSA capsules. This method is a powerful, nondestructive visualization technique for the characterization and visualization of structures on the surface and inside of particles (Lamprecht et al., 2000). Therefore, HSA capsules in micron range were prepared as a model for nanocapsules. HSA and FA were labeled prior to capsule production with the fluorescent dyes FITC and fluorescent mega red 520 NHS-ester, respectively.

No aggregate formation occurred between capsules, single capsules in micron range were clearly visible (Fig. 3). Using this method we observed that within the same batch some single capsules were completely modified with FA while others did not show any FA derived fluorescence signal (Fig. 3). Albert et al. (1952) had already described in 1952 that pteridines have the ability to form strong intermolecular hydrogen bonds through amino- and hydroxyl substituents and the heterocyclenitrogens. Due to the fact that FA contains the structural element of pteridine this phenomenon could be explained by the strong intermolecular attraction of FA molecules.

The three dimensional reconstruction of a single capsule showed a shell of HSA that is surrounding a cavity into which drugs could be loaded. FA is clearly located on the surface of the HSA capsule. In the reconstruction image FA is not completely surrounding the capsule. This is most likely an artifact due to signal loss of fluorescent red by high laser energy input during the scanning process ("photo bleaching" effect).

\subsection{Cell studies}

Previous studies have shown that macrophage activation plays a significant role in the pathogenesis of RA (Schett, 2008; Xia et al., 2009). The expression of FR $\beta$ by activated macrophages in the inflamed sites of RA (Turk et al., 2002; Van Der Heijden et al., 2009; Nakashima-Matsushita et al., 1999), allows the use of this receptor as a target for the specific delivery of therapeutic agents. In the present study, we evaluated the binding and internalization of FA-HSA nanocapsules (a potential folate-conjugated drug delivery system) by human FR $\beta$-expressing macrophages using flow cytometry. FR $\beta$-expressing macrophages (Fig. 4) showed an increased binding for capsules with FA when compared with those without FA (Fig. 4). Moreover, the observed binding recedes when incubation occurs at $4{ }^{\circ} \mathrm{C}$ when the internalization is not allowed (Fig. 4), suggesting that capsules are being internalized by macrophages. This conclusion is supported by the results observed after the acidic vs. neutral wash of macrophages incubated with capsules. Since the acidic wash eliminates any surface-bound capsules while the neutral wash only washes away unbound capsules, and no difference in the mean fluorescence intensity was observed between the two conditions (Fig. 4), we conclude that the observed fluorescence is due to internalized capsules. No significant difference was observed between nanocapsules with 0.38 and 6.42 molecules FA per molecule HSA, when nanocapsules with different amounts of FA linked on the capsule surface were compared. This suggests that a maximum of 0.38 molecules FA per HSA molecule is sufficient for efficient FA-HSA targeting of macrophages.

The specificity of FA-HSA nanocapsules for FR $\beta$-expressing macrophages was further evaluated by incubating FR $\beta$-positive and FR $\beta$-negative macrophages with FA-HSA nanocapsules containing 0.38 molecules FA per molecule HSA. The internalization of the FA-nanocapsules was higher in FR $\beta$-positive macrophages (mean fluorescence intensity of $2.58 \pm 0.68$ ) than in macrophages not expressing FR $\beta$ (mean fluorescence intensity of $1.67 \pm 0.15$ ), indicating that the binding/internalization of capsules is mediated through folate receptors. It has been reported that the reduced folate carrier, another protein used for folate transport in cells,

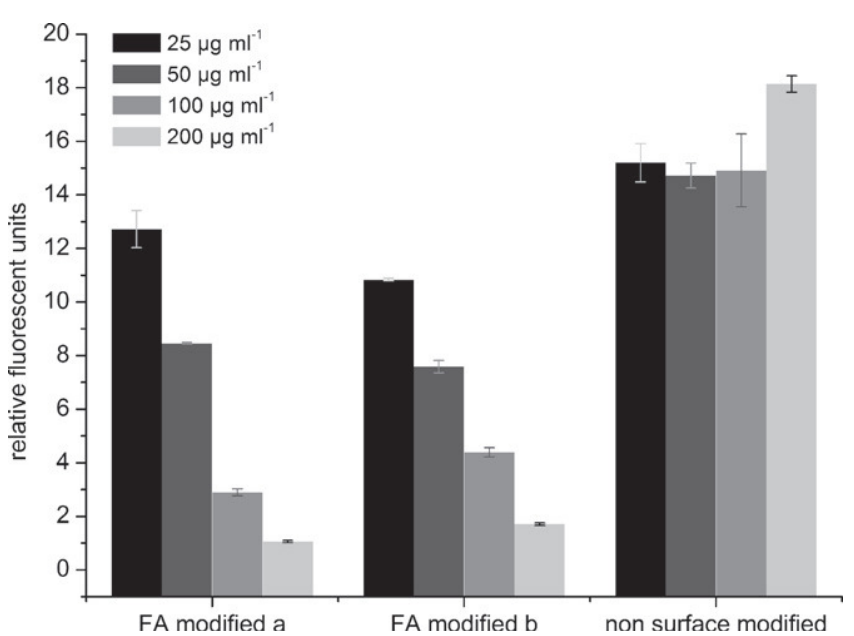

Fig. 5. Viability of macrophages in the presence of different concentrations of HSA nanocapsules after incubation time of $24 \mathrm{~h}$. Viability was analyzed using the resazurin assay and it is expressed as Relative Fluorescent Units.

does not transport folate conjugates (Paulos et al., 2004) such as the capusles developed in this study, therefore the internalization of FA-HSA nanocapsules must be mediated through FR $\beta$.

The viability of macrophages in the presence of nanocapsules was also evaluated. The incubation of macrophages with FAmodified HSA nanocapsules reduced viability in a concentrationdependent manner (Fig. 5). No toxicity was observed for HSA capsules (Fig. 5), as these are not internalized by macrophages (Fig. 4).

\section{Conclusion}

This work demonstrates the production of stable, uniform (size) HSA nanocapsules avoiding toxic crosslinking agents and emulsifiers. HSA nanocapsules in a size range of $440 \mathrm{~nm}$ were surface modified using different amounts of FA to allow for specific cell internalization by FR $\beta$ positive macrophages. Size, PDI and zetapotential were determined before and after surface modification. Using CLSM analysis it was found that FA modification is not uniform due to strong intermolecular attraction of FA molecules. Furthermore specific binding and internalization of FA modified HSA-nanocapsules by FR $\beta$-positive macrophages was achieved in comparison with non-modified nanocapsules. In addition, the internalization of the FA-modified nanocapsules was three-fold higher in FR $\beta$-positive macrophages than in macrophages not expressing FR $\beta$, showing that the binding/internalization of capsules is being mediated through folate receptors. Further studies should include an internalization evaluation using other cell types to confirm specificity, as well as surface modification with other target molecules to enhance specificity of macrophage internalization. The folate based nanodevice produced during this study could be used to deliver therapeutic agents to activated macrophages without affecting normal cells and tissues. Consequently, future investigation should focus on loading the nanodevices with different drugs suitable for the treatment of RA.

\section{Acknowledgements}

This work has received funding from the European Union Seventh Framework Programme (FP7/2007-2013) under grant agreement NMP4-LA-2009-228827 NANOFOL. We thank the Instituto Português do Sangue (IPS, Porto, Portugal) for providing buffy coats from informed healthy volunteers and Exbio from Czech Republic for providing antibodies. 


\section{References}

Adamopoulos, I.E., Sabokbar, A., Wordsworth, B.P., Carr, A., Ferguson, D.J., Athanasou, N.A., 2006. Synovial fluid macrophages are capable of osteoclast formation and resorption. J. Pathol. 208, 35-43.

Ahsan, F., Rivas, I.P., Khan, M.A., Torres Suarez, A.I., 2002. Targeting to macrophages: role of physicochemical properties of particulate carriers - liposomes and microspheres - on the phagocytosis by macrophages. J. Control. Release 79 $29-40$.

Albert, A., Brown, D.J., Cheeseman, G., 1952. 812. Pteridine studies. Part III: the solubility and the stability to hydrolysis of pteridines. J. Chem. Soc., 4219-4232.

Bradford, M.M., 1976. A rapid and sensitive method for the quantitation of microgram quantities of protein utilizing the principle of protein-dye binding. Anal. Biochem. 72, 248-254

Desai, M.P., Labhasetwar, V., Amidon, G.L., Levy, R.J., 1996. Gastrointestinal uptake of biodegradable microparticles: effect of particle size. Pharm. Res. 13,1838-1845.

Gabizon, A., Horowitz, A.T., Goren, D., Tzemach, D., Mandelbaum-Shavit, F., Qazen, M.M., Zalipsky, S., 1999. Targeting folate receptor with folate linked to extremities of poly(ethylene glycol)-grafted liposomes: in vitro studies. Bioconjug. Chem. 10, 289-298.

Grinstaff, M.W., Suslick, K.S., 1991. Air-filled proteinaceous microbubbles: synthesis of an echo-contrast agent. PNAS 88, 7708-7710.

Grinstaff, M.W., Suslick, K.S., 1992. Proteinaceous microspheres. Am. Chem. Soc., 218-226.

Kim, Y.K., Choi, J.Y., Yoo, M.K., Jiang, H.L., Arote, R., Je, Y.H., Cho, M.H., Cho, C.S. 2007. Receptor-mediated gene delivery by folate-PEG-baculovirus in vitro. J. Biotechnol. 131, 353-361.

Lamprecht, A., Schäfer, U., Lehr, C.M., 2000. Structural analysis of microparticles by confocal laser scanning microscopy. AAPS PharmSci 1, 10-19.

Langer, K., Balthasar, S., Vogel, V., Dinauer, N., von Briesen, H., Schubert, D., 2003. Optimization of the preparation process for human serum albumin (HSA) nanoparticles. Int. J. Pharm. 257, 169-180.

Mohanraj, V.J., Chen, Y., 2006. Nanoparticles - a review. Trop. J. Pharm. Res. 5, $561-573$.

Müller, B.G., Leuenberger, H., Kissel, T., 1996. Albumin nanospheres as carriers for passive drug targeting: an optimized manufacturing technique. Pharm. Res. 13 , 32-37.

Nakashima-Matsushita, N., Homma, T., Yu, S., Matsuda, T., Sunahara, N., Nakamura, T., Tsukano, M., Ratnam, M., Matsuyama, T., 1999. Selective expression of folate receptor $\beta$ and its possible role in methotrexate transport in synovial macrophages from patients with rheumatoid arthritis. Arthritis Rheum. $42,1609-1616$
Panyam, J., Labhasetwar, V., 2003. Biodegradable nanoparticles for drug and gene delivery to cells and tissue. Adv. Drug Deliv. Rev. 55, 329-347.

Paulos, C.M., Turk, M.J., Breur, G.J., Low, P.S., 2004. Folate receptor-mediated targeting of therapeutic and imaging agents to activated macrophages in rheumatoid arthritis. Adv. Drug Deliv. Rev 56, 1205-1217.

Puig-Kröger, A., Sierra-Filardi, E., Dominguez-Soto, A., Samaniego, R., Corcuera, M.T., Gomez-Aguado, F., Ratnam, M., Sanchez-Mateos, P., Corbi, A.L., 2009. Folate receptor $\beta$ is expressed by tumor-associated macrophages and constitutes a marker for M2 anti-inflammatory/regulatory macrophages. Cancer Res. 69, 9395-9403.

Ross, J.F., Wang, H., Behm, F.G., Mathew, P., Wu, M., Booth, R., Ratnam, M., 1999. Folate receptor type $\beta$ is a neutrophilic lineage marker and is differentially expressed in myeloid leukemia. Cancer 85, 348-357.

Schett, G., 2008. Review: immune cells and mediators of inflammatory arthritis. Autoimmunity 41, 224-229.

Sebak, S., Mirzaei, M., Malhotra, M., Kulamarva, A., Prakash, S., 2010. Human serum albumin nanoparticles as an efficient noscapine drug delivery system for potential use in breast cancer: preparation and in vitro analysis. Int. J. Nanomed. 5, 525-532.

Silva, R., Ferreira, H., Cavaco-Paulo, A., 2011. Sonoproduction of liposomes and protein particles as templates for delivery purposes. Biomacromolecules 12 3353-3368.

Stella, B., Arpicco, S., Peracchia, M.T., Desmaele, D., Hoebeke, J., Renoir, M., D’Angelo, J., Cattel, L., Couvreur, P., 2000. Design of folic acid-conjugated nanoparticles for drug targeting. J. Pharm. Sci. 89, 1452-1464.

Suri, S., Fenniri, H., Singh, B., 2007. Nanotechnology-based drug delivery systems. J. Occup. Med. Toxicol. 2, 16.

Turk, M.J. Breur, G.J., Widmer, W.R, Paulos, C.M., Xu, L.C., Grote, L.A., Low, P.S 2002. Folate-targeted imaging of activated macrophages in rats with adjuvantinduced arthritis. Arthritis Rheum. 46, 1947-1955.

Ulbrich, K., Michaelis, M., Rothweiler, F., Knobloch, T., Sithisarn, P., Cinatl, J., Kreuter Jr., 2011. Interaction of folate-conjugated human serum albumin (HSA) nanoparticles with tumour cells. Int. J. Pharm. 406, 128-134.

Van Der Heijden, J.W., Oerlemans, R., Dijkmans, B.A.C., Qi, H., Laken, C.J.V., Lems, W.F., Jackman, A.L., Kraan, M.C., Tak, P.P., Ratnam, M., Jansen, G., 2009. Folate receptor $\beta$ as a potential delivery route for novel folate antagonists to macrophages in the synovial tissue of rheumatoid arthritis patients. Arthritis Rheum. 60,12-21.

Witus, L.S., Francis, M.B., 2011. Using synthetically modified proteins to make new materials. Acc. Chem. Res. 44, 774-783.

Xia, W., Hilgenbrink, A.R., Matteson, E.L., Lockwood, M.B., Cheng, J.X., Low, P.S., 2009. A functional folate receptor is induced during macrophage activation and can be used to target drugs to activated macrophages. Blood 113, 438-446. 